\title{
Lymph Node State
}

National Cancer Institute

\section{Source}

National Cancer Institute. Lymph Node State. NCI Thesaurus. Code C124448.

A condition or state of a lymph node at a particular time. 